$B N W L-5 A-90$
$B H-90$

UL 161965

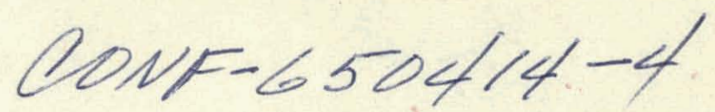

ELECTRON MICROSCOPE STUDIES OF

\title{
SECOND PHASE PARTICLES IN DILUTE ALLOYS OF URANIUM
}

by

B。 Mastel, T。K。Bierlein, and C。 L。Corey*

March 3, 1965

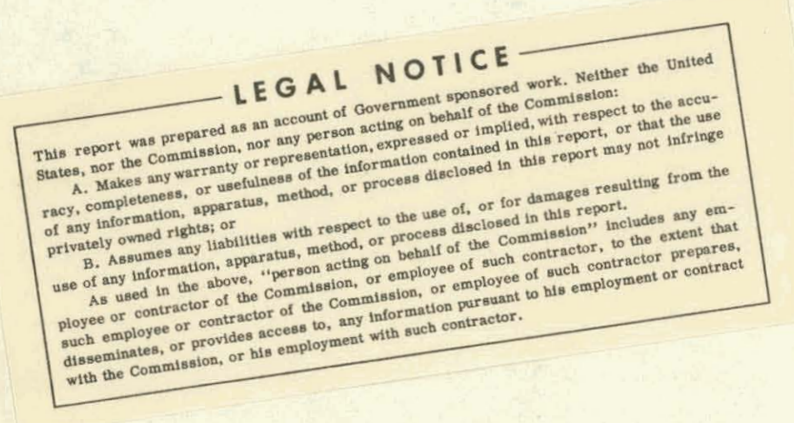

BATTELLE-NORTHWEST

Pacific Northwest Laboratory

a division of

BATTELIE MEMORIAL INSTITUTE

Richland, Washington

PATENT CLEARANCE OBTAINED. REEEASE TO

THE PUBLIC IS APPROVED. PROCEDURES

ARE ON FILE IN THE RECEIVING SECTION

* This work was supported by the U。S。Atomic Energy Commission under Contract $\operatorname{AT}(45-1)-1830$ 。 


\section{DISCLAIMER}

This report was prepared as an account of work sponsored by an agency of the United States Government. Neither the United States Government nor any agency Thereof, nor any of their employees, makes any warranty, express or implied, or assumes any legal liability or responsibility for the accuracy, completeness, or usefulness of any information, apparatus, product, or process disclosed, or represents that its use would not infringe privately owned rights. Reference herein to any specific commercial product, process, or service by trade name, trademark, manufacturer, or otherwise does not necessarily constitute or imply its endorsement, recommendation, or favoring by the United States Government or any agency thereof. The views and opinions of authors expressed herein do not necessarily state or reflect those of the United States Government or any agency thereof. 


\section{DISCLAIMER}

Portions of this document may be illegible in electronic image products. Images are produced from the best available original document. 
ELECTRON MICROSCOPE STUDIES OF

SECOND PHASE PARTICLES IN DILUTE ALLOYS OF URANTUM

B. Mastel, T。K。Bierlein, and C。 L。Corey

\section{INTRODUCTION}

This report describes techniques of transmission electron microscopy for determining particle size and density in uranium rich alloys Uranium that contains small amounts of alloying elements and that has had appropriate heat treatment offers remarkable resistance to swelling during irradiation (1)。 An explanation is that alloying elements are present as precipitate particles, the number and size of which alter the swelling characteristics. Several investigam tors have utilized electron microscopy to examine replicas from which the size and density of second phase particles in uranium rich alloys were determined. The present study corroborates results obtained by the replica technique. In addition, the transmission microscopy technique reveals very small particles which are below the limit of resolution of the replica technique.

\section{EXPERIMENTAL CONSIDERATIONS}

The two alloys investigated were fdentical to those described previously by Woods $(2)$. Second phase particles were delineated by an electropolisho electroetch followed by replication with cellulose acetate。 The final electron micrographs were then analyzed with a Zeiss Particle Size Analyzer。 'Ihe method used by Woods, et al has several limitations because (1) surtace roughening takes place during electropolishing and small particles are obscured by the background structure, (2) particles smaller than $800 \mathrm{~A}$, a reasonable lower limit. 
of resolution, are neglected, and (3) lattice defects, such as dislocations, which may be associated with particles and possibly influence the properties of the metal are ignored by replica techniques. Transmission electron microscopy was therefore applied to the problem of determining the size and density of small particles in uranium.

Specimens for transmission electron microscopy are usually foils that are thinned just before final viewing. Bulk samples cannot be rolled into the more convenfent thin sheet form without altering the size and distribution of particles; therefore, electron microscope specimens for this study were prepared directly from the bulk samples. Rods, $3 \mathrm{~mm}$ in diameter, were machined from the bulk samples and embedded in a self-curing resin. The rods were sectioned into 0.5 mm thick wafers by a watermcooled diamond saw, (3) and the wafers were made half as thick by mechanically polishing both sides through coarse diamond paste. Final thinning was performed with a fine electrolytic jet, because the small size of the wafers precluded use of the conventional window method for electrolytic thinning. During jet polishing, the specimen was held in a 3-mm diameter recess in a $20 \mathrm{~cm}$ long, stainless steel holder. An insulating lacquer applied to the end of the holder and the edge of the wafer localized the action of the electrolyte. A drawn down glass" tube containing a platinum cathode served as the jet。 With tip of the jet $1 \mathrm{~cm}$ from the sample and a current density of $0.2 \mathrm{amps} / \mathrm{cm}^{2}$ pitting was negligible. The electrolyte consisted of 85 percent orthophosphoric acid in water. (4)

A stationary jet tip produces a spherical dimple; whereas, a moving tip produces a flat dimple. After a dimple is formed on one side, jetting is stopped 
and the sample is removed from the holder. The dimpled surface is painted with insulating lacquer and reinserted in the holder so the undimpled surface can be Jet polished. A strong light source is focused on the specimen which is viewed by a low power stereo microscope. The electrolytic jetting is stopped as soon as light is transmitted through the insulating lacquer on the back of the sample. The wafer is then carefully cleaned in several washes of acetone and given a second electropolish. The second treatment removes the oxide layer formed on the specimen during thinning and passivates the surface with respect to oxidation (4)。

\section{QUANTITATIVE MEASUREMENTS}

Samples for transmission electron microscopy are thin foils 100 to $2000 \mathrm{~A}$ thick depending on the material being investigated. From replica studies, it was apparent that the diameter of the larger particles would be greater than the foil thickness. On the other hand, small particles would be on either surface in addition to being enclosed within the foil. Special considerations must therefore be given to the sample thickness。Consider a foil having thickness, $t$, which contains particles havịng identical diameters, $D$ 。

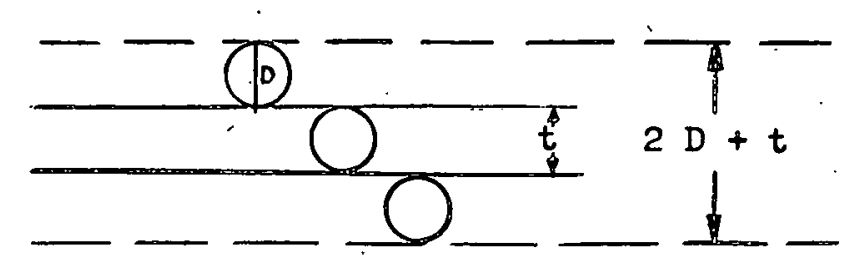



and the summation is made over the $i$ classes. A simpler solution for obtaining particle density from transmission micrographs has been proposed by Hilliard in which particles are considered as being enclosed within the foil only (5). This solution is valid only when the particle diameter is small in relation to the foil thickness。

\section{RESULTS}

Samples of high purity uranium that have been thinned by the method described are similar to those described by other investigators ${ }^{(6)}$. Second phase particles are not observed. However, the alloyed uranium specimens did disclose the presence of particles. Figure 1 is a transmission electron micrograph of an alpha rolled alloy that contains $185 \mathrm{ppm}$ Fe and $95 \mathrm{ppm}$ Si。 The large precipitated particles appear dark, and are frequently surrounded by a network of dislocations。 The shape of the particles cannot be determined unambiguously by transmission electron microscopy. It is inferred that the particles are spherical, because rod and plate-like particles are not observed. Attempts to. identify the particles by electron diffraction failed; presumably the particles are rounded and do not permit sufficient penetration of the electron beam. Particle size-frequency determinations by replica techniques showed that the most prevalent diameter of particles in this alloy is approximately 0.2 micron. This was confirmed by trans mission microscopy. The average diameter of a total of 50 spherical particles measured on transmission micrographs was 0.21 micron, and all diameters were 0.1 to 0.3 micron. For a foil thickness of $250 \mathrm{~A}, \mathrm{a}$ density of $4.4 \times 10^{11}$ particles/ce was calculated from transmission micrographs prepared from the above described alloy. This value agrees very well with the value $5.1 \times 10^{11}$ particles/cc determined from replicas. 
Figure 2 is a transmission micrograph of an alloy with an identical compo sition, but with a different heat treatment. The alloy was betamquenched and aged one hour at $590 \mathrm{C}$. Quantitative metallography , based on replica techniques, predicted the presence of many particles having diameters less than $800 \mathrm{~A}_{2}$ the lower limit of resolution of the technique. The diameter of the particles observed by transmission microscopy ranged from $100 \mathrm{~A}$ to $3000 \mathrm{~A}$. In fact, most particles had diameters less than $1000 \mathrm{~A}$, in good agreement with the predictions based on replica results. Unfortunately, small particles are of the same size as dislocations and loops, and differentiation of these small particles is difficult. Because most particles were opaque to the electron beam, they were not tilt sensitive. Several micrographs of a given area of the specimen at various orientations were obtained and analyzed. Only those spots or particles were measured which were not tilt sensitive。

The particle density of this specimen had been estimated at $4.2 \times 10^{11}$ particles/cc by replica techniques. The density of particles with diameters greater than $800 \mathrm{~A}$ derived from transmission electron micrographs and the mathematical relationship given above yielded a value of $3.2 \times 10^{11}$ particles/cc, again in govb agreement with the value derived from replicas. In a similar fashion the density of particles with diameters smaller than $800 \mathrm{~A}$ was estimated from the transmission micrographs and a value of $4.3 \times 10^{14}$ particles/ce was obtained. This density is three orders of magnitude greater than the density ascribable to particles with diameters greater than $800 \mathrm{~A}$. This difference most certainly emphasizes the value of high resolution electron transmission microso copy in the determination of particle size and frequency. 
SUMMARY AND CONCLUSIONS

Transmission electron microscopy has been successfully utilized to study particle size density distributions in dilute alloys of uranium. The results of a quantitative metallographic procedure used for determining particle sizedensity distributions from transmission electron micrographs agree well with that derived from replica electron micrography, The increase in resolution inherent in transmission techniques permits inclusion of particles normally too small to be resolved by replica methods. 
REFERENCES

1. Quarterly Progress Report - Metallurgy Research Operation, July, August, September, 1964, edited by J。J.Cadwell, HW 84281 .

2. Ko N。Woods, R。 D。 Leggett and $Y_{0} E_{0}$ Smith, "Precipitate Particles in Dilutely Alloyed Uranium o Quantitative Metallography," HW-80349.

3. B。 Mastel and H。 E。 Kissinger, "Wafering of Burk Specimens For Transmission Electron Microscopy $"$ J. Sci.Inst。 4I, 510-511, August 1964。

4. B。 Hudson and $\mathrm{K}$. Ho Westmacott, "Dislocation Loops and Irradiation Growth In Alpha Uranium," AERE $=R 3752,1961$.

5. J. E。 Hilliard, "The Counting and Sizing of Particles In Transmission Microscopy " Report No。61-RL-2885M, General Electric Company。 December 1961。

6. C. L. Angerman, "Transmission Electron Microscopy of Uranium," $\mathrm{J}_{0}$-Nuclear Materials, 9, 109-112, 1963. 


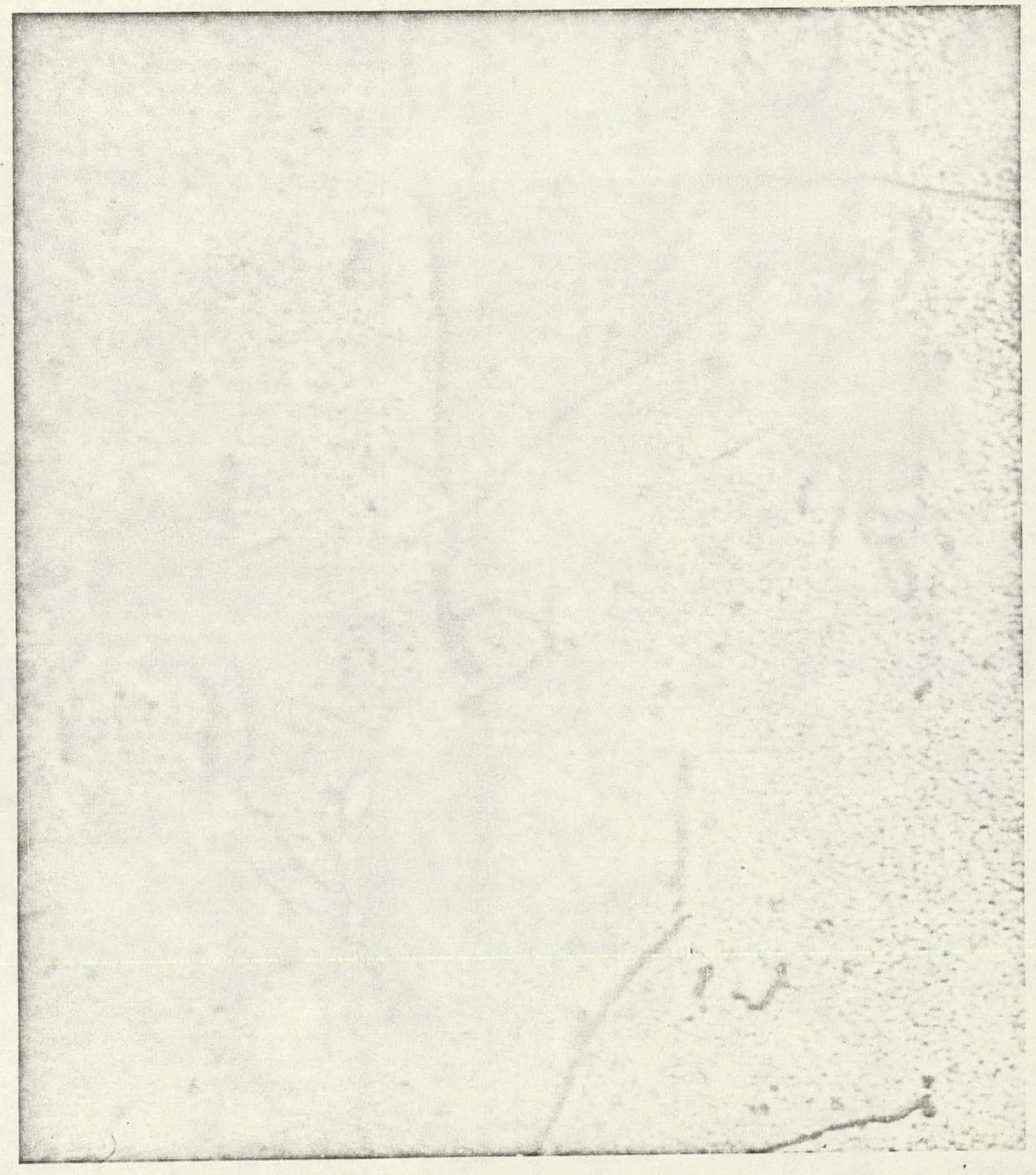

FIGURE l。

Transmission Electron Micrograph of Alpha Rolled Uranium Containing 185 ppm Fe and 95 ppm Si Showing Second Phase Particles and Dislocation Networks.

$75,000 x$ 


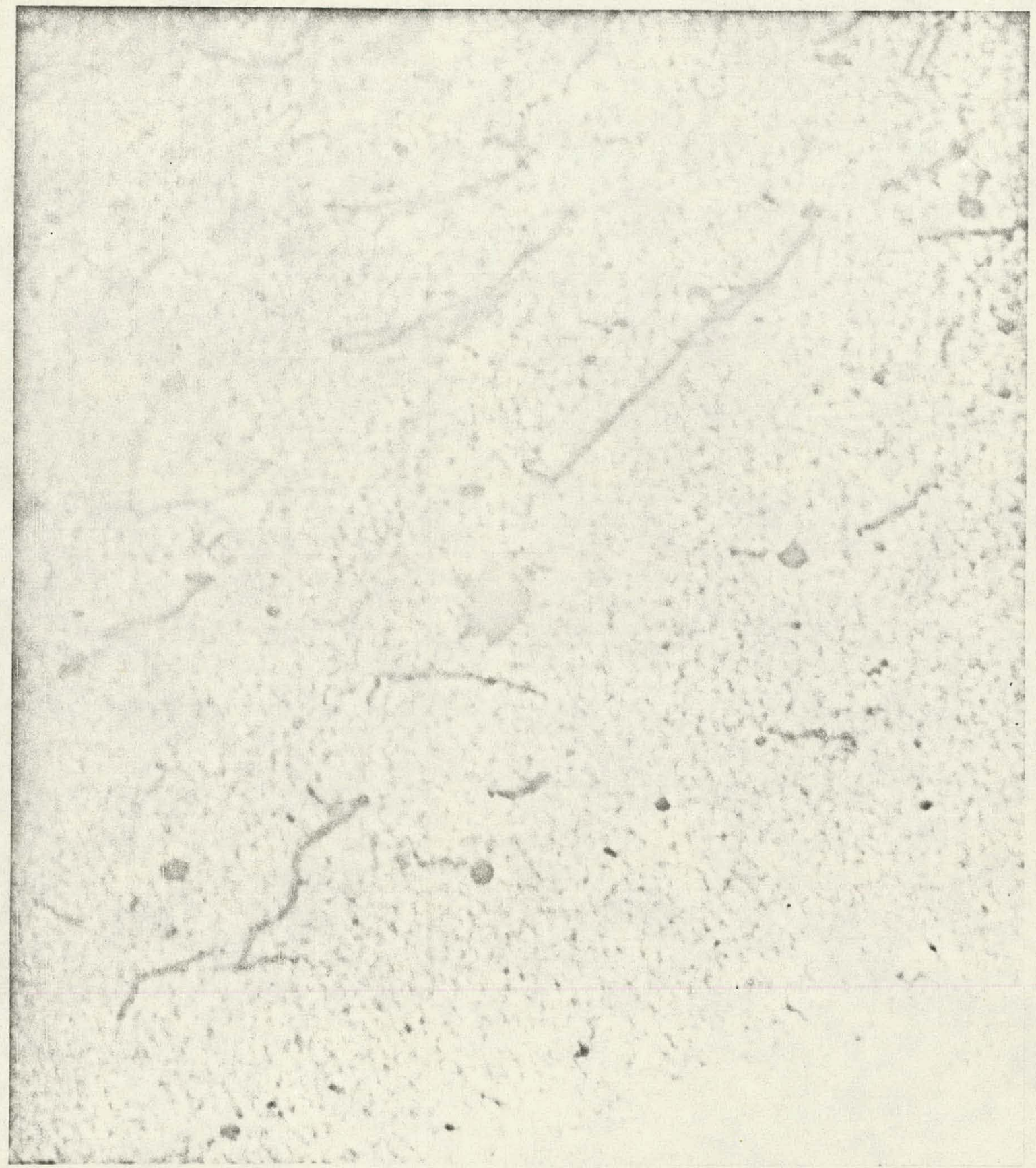

FIGURE 2。

Transmission Electron Micrograph of Uranium Containing $185 \mathrm{ppm} \mathrm{Fe}$ and $95 \mathrm{ppm}$ Si Showing Second Phase Particles After the Alloy Had Been Alpha Rolled, Beta-quenched, and then Aged $1 \mathrm{hr}$ at $590^{\circ} \mathrm{C}$ Prior to Thinning.

$100,000 x$ 